\title{
Soft drink consumption and mental health problems among adults in Australia
}

\author{
Zumin Shi ${ }^{1,2, *}$, Anne W Taylor ${ }^{1,2}$, Gary Wittert ${ }^{2}$, Robert Goldney ${ }^{3}$ and Tiffany K Gill ${ }^{1,2}$ \\ 'Population Research and Outcome Studies Unit, Department of Health, PO Box 287, Rundle Mall, South \\ Australia 5000, Australia: ${ }^{2}$ Department of Medicine, University of Adelaide, Adelaide, South Australia, \\ Australia: ${ }^{3}$ Discipline of Psychiatry and the Hanson Institute, University of Adelaide, Adelaide, South Australia, \\ Australia
}

Submitted 31 March 2009: Accepted 30 November 2009: First published online 15 January 2010

\begin{abstract}
Objective: To examine the association between soft drink consumption and mental health problems, including self-reported doctor-diagnosed anxiety, stressrelated problem and depression, suicidal ideation and psychological distress, among adults in South Australia.

Design: Data were collected using a risk factor surveillance system. Each month a representative random sample of South Australians was selected from the Electronic White Pages with interviews conducted using computer-assisted telephone interviewing.

Setting: South Australia.

Subjects: Participants were aged 16 years and above.

Results: Among 4741 participants, $12 \cdot 5 \%$ reported daily soft drink consumption of more than half a litre. High levels of soft drink consumption were positively associated with depression, stress-related problem, suicidal ideation, psychological distress and a current mental health condition, but not anxiety. Overall, $24.0 \%$ of those having suicidal ideation reported consuming more than half a litre of soft drink per day. In the multivariate analysis, after adjusting for sociodemographic and lifestyle factors, those who consumed more than half a litre of soft drink per day had approximately $60 \%$ greater risk of having depression, stress-related problem, suicidal ideation, psychological distress or a current mental health condition, compared with those not consuming soft drinks. The soft drink to total fluid consumption ratio had similar associations with mental health problems.

Conclusions: There is a positive association between consumption of soft drinks and mental health problems among adults in South Australia.
\end{abstract}

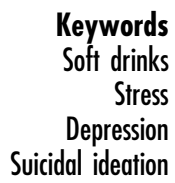

There is a relationship between nutrition and depression $^{(1-3)}$. Deficiencies of folate, vitamin $\mathrm{B}_{12}, \mathrm{Fe}, \mathrm{Zn}$ and Se tend to be more common among depressed than non-depressed persons ${ }^{(2)}$. Adherence to a Mediterranean dietary pattern has been linked to depression prevention in a previous cohort study ${ }^{(3)}$. An ecological study suggested a positive association between sugar consumption and depression ${ }^{(4)}$. The protective effect of $n-3$ fatty acids on depression has also been documented ${ }^{(2,5)}$.

Soft drink consumption has become a public health concern because of its association with many medical conditions including obesity, diabetes and dental caries ${ }^{(6,7)}$. The intake of soft drinks in Australia has grown rapidly from around $47 \cdot 3$ litres per person per year in 1969 to 113 litres per person (children and adults) in $1999^{(8)}$. Soft drink consumption increases the level of insulin resistance ${ }^{(9,10)}$, diabetes ${ }^{(11,12)}$ and obesity ${ }^{(13)}$. These conditions are all related to depression. A crosssectional study from Norway linked soft drinks with hyperactivity, mental distress and conduct problems among adolescents ${ }^{(14)}$. Little is known as to whether there is a direct association between soft drink consumption and mental health problems among adults and there are no population studies that have been done in this field. Moreover, any such relationship may be bidirectional, as previously shown in relation to folate consumption, obesity and mental health ${ }^{(15,16)}$. Using data from the South Australian Monitoring and Surveillance System (SAMSS), the objective of the present study was to describe the association between soft drink consumption and mental health problems among adults in South Australia. 


\section{Methods}

\section{Survey design and sample selection}

Data for the present study were collected using the SAMSS from March 2008 to December 2008. SAMSS is designed to systematically monitor the trends of diseases, health-related problems, risk factors and other health service issues for all ages over time for the South Australian (SA) health system ${ }^{(17)}$. Interviews are conducted on a minimum of 600 randomly selected people (of all ages) each month. All households in SA with a telephone connected and the telephone number listed in the Electronic White Pages are eligible for selection in the sample. A letter introducing the survey is sent to the selected household and the person with the last to have a birthday within a 12-month period is chosen for interview. There are no replacements for non-respondents. Up to ten call backs are made to the household to interview the selected persons. Interviews are conducted by trained health interviewers. SAMSS utilises a computer-assisted telephone interviewing system to conduct the interviews. Data are weighted by area (metropolitan/rural), age, gender and probability of selection in the household to the most recent SA population data, so that the results are representative of the SA population ${ }^{(18)}$.

In the period March 2008 to December 2008 a total of 5961 interviews were conducted $(62 \cdot 1 \%$ response rate). The questions related to having a mental health problem are asked only of respondents aged 16 years and over. The present analysis is therefore limited to 4741 respondents.

\section{Data items}

\section{Mental illness}

Suicidal ideation is based on four questions contained in the twenty-eight-item General Health Questionnaire $(\mathrm{GHQ}-28)^{(19)}$. These are: 'Over the past few weeks have you...' '...felt that life isn't worth living?', '...thought of the possibility that you might do away with yourself?', '...f found yourself wishing you were dead and away from it all?' and '...found that the idea of taking your own life kept coming into your mind?' The first and third questions have the responses of 'not at all', 'no more than usual', 'rather more than usual' or 'much more than usual'; and the second and fourth have the responses of 'definitely not', 'I don't think so', 'has crossed my mind' or 'definitely has'. The questions are scored by applying the binary method to the four questions to produce a score ranging from 0 to 4 , where a score of 1 or more indicated suicidal ideation $^{(20,21)}$. The inclusion of suicidal ideation questions in a surveillance system initially highlighted some methodological issues, with concerns expressed by interviewers and ethics consultants regarding the sensitive, and perhaps influencing, nature of the four questions. Specialist psychiatric advice was obtained which indicated little cause for concern. Notwithstanding, a toll-free number, providing mental health advice, is offered to all respondents.

Other questions related to mental health included having been diagnosed by a doctor in the previous 12 months with anxiety, depression, a stress-related problem or another mental health problem. Self-reported current mental health problem is defined as either reporting doctor-diagnosed mental health problems, or currently receiving treatment for anxiety, depression, stress-related problem or another mental health problem. The level of psychological distress of respondents was determined using the Kessler Psychological Distress ten-item scale $(\mathrm{K} 10)^{(22)}$. This scale was developed to measure anxiety and depressive disorders in a general population. The response categories of each of the ten questions are converted to Likert scales and reversescored. The ten items in the scale are summed to give scores ranging from 10 (no distress) to 50 (high risk of anxiety or a depressive disorder). The scores are grouped in four categories: low (10-15), moderate (15-21), high (22-29) and very high (30-50). Participants having a K10 score higher than 22 were defined as having psychological distress ${ }^{(22)}$.

\section{Soft drink, fruit and vegetable consumption}

Soft drink consumption was assessed by the question 'On average, how many litres of soft drink and sports drink (e.g. Coke, lemonade, flavoured mineral water, Powerade, Gatorade) do you usually have in a day?' Participants were also asked how many glasses of water and juice they have in a day. Total fluid consumption was constructed based on the consumption (in litres) of soft drink, water and fruit or vegetable juice. Participants were asked how many servings of fruit and vegetables they usually ate per day. The fruit and vegetable consumption variable was divided into those eating less than current government recommendations (two servings of fruits and five servings of vegetables per day) and those eating at the recommendation level or more ${ }^{(23)}$.

\section{Demographic variables}

Sex, age, area of residence, highest educational attainment and gross annual household income were included in the analyses.

\section{History of chronic diseases}

Participants were asked whether they had medically confirmed diabetes, current asthma, CVD (heart attack, angina, heart disease and/or stroke), arthritis, osteoporosis or chronic obstructive pulmonary disease (COPD). These conditions were used to calculate the number of chronic conditions.

\section{Other measurements}

A measure of physical activity was derived from the sum of the time spent undertaking walking, moderate and/or vigorous activity in a one-week period, with vigorous activity doubled to account for its greater intensity ${ }^{(24)}$. Sufficient activity to provide a health benefit was defined 
as physical activity greater than or equal to $150 \mathrm{~min} /$ week. BMI was derived from self-reported weight and height. Overweight was defined as $\mathrm{BMI} \geq 25 \mathrm{~kg} / \mathrm{m}^{2}$. Smoking status and alcohol intake were also determined.

\section{Data analyses}

The $\chi^{2}$ test was used to compare differences in categorical variables. In order to exclude the possible confounding of total fluid needs, a soft drink to total fluid consumption ratio was constructed. The association between soft drink consumption, soft drink:total fluid ratio and the risk of mental illness was analysed using logistic regression models, adjusting for multiple covariates. The logistic model controlled for age (continuous), gender, education, income, residence, smoking, alcohol consumption, physical activity, intake of fruit and vegetables, overweight and chronic disease (diabetes, asthma, CVD, arthritis, osteoporosis, COPD). A test for trend of the risk of mental illness across groups of soft drink consumption was undertaken by putting median intake in each group as continuous variables in the logistic regression. Statistical significance was considered when $P<0.05$ (two-sided). All data presented herein are weighted by age, sex, area of residence to the latest Census or Estimated Residential Population from the Australian Bureau of Statistics, and the probability of selection in the household. All analyses were performed using the STATA statistical software package version 10 (StataCorp, College Station, TX, USA).

\section{Results}

Overall, 4741 adults aged 16 years and above (mean $46 \cdot 7$ years, $48 \cdot 1 \%$ male) were interviewed. The prevalence of doctor-diagnosed mental illness was 5.2\% (anxiety), 6.9\% (depression) and $4 \cdot 4 \%$ (stress-related problem). The prevalence of suicidal ideation was $4 \cdot 6 \%$. In addition, $9 \cdot 0 \%$ of the participants had psychological distress according to the K10 score. Overall, $14.0 \%$ of the participants reported a diagnosed and/or treated mental health condition.

About $70 \%$ of the participants reported no consumption of soft drinks, while $12 \cdot 5 \%$ had a daily soft drink intake of half a litre or more (Table 1 ). In total, $6.6 \%$ of the participants had soft drink:total fluid ratio of 0.5 or greater. Among those with suicidal ideation, $24 \cdot 1 \%$ consumed half a litre or more of soft drink per day.

High levels of soft drink consumption were positively associated with depression, suicidal ideation, psychological distress and a current mental health condition, but not anxiety (Table 2). The positive association between soft drink consumption and stress approached significance. Compared with non-consumers of soft drinks, those consuming half litre or more of soft drink had a much higher prevalence of psychological distress (15.0\% $v$. $7 \cdot 7 \%$ ). Similar associations were found between the soft drink:total fluid ratio and mental illness.
Table 1 Characteristics of the South Australian Monitoring and Surveillance System (SAMSS) sample aged 16 years and above during March 2008-December 2008

\begin{tabular}{|c|c|c|}
\hline & $n$ & $\%$ \\
\hline \multicolumn{3}{|l|}{ Gender } \\
\hline Male & 2311 & $48 \cdot 7$ \\
\hline Female & 2431 & $51 \cdot 3$ \\
\hline \multicolumn{3}{|l|}{ Gross annual household income (\$AU) } \\
\hline$\geq 20000$ & 3365 & $71 \cdot 0$ \\
\hline$<20000$ & 516 & $10 \cdot 9$ \\
\hline Not stated & 860 & $18 \cdot 2$ \\
\hline \multicolumn{3}{|l|}{ Education } \\
\hline Low (no schooling to secondary) & 2566 & $54 \cdot 2$ \\
\hline Medium (trade, certificate, diploma) & 1108 & $23 \cdot 4$ \\
\hline High (degree or higher) & 1057 & $22 \cdot 4$ \\
\hline \multicolumn{3}{|l|}{ Residence } \\
\hline Urban (metropolitan, Adelaide) & 3443 & $72 \cdot 6$ \\
\hline Rural (SA country) & 1298 & $27 \cdot 4$ \\
\hline \multicolumn{3}{|l|}{ Smoking status } \\
\hline Non-smoker & 2261 & $47 \cdot 7$ \\
\hline Ex smoker & 1763 & $37 \cdot 2$ \\
\hline Smoker & 718 & $15 \cdot 1$ \\
\hline Diabetes & 342 & $7 \cdot 2$ \\
\hline COPD & 212 & $4 \cdot 5$ \\
\hline Asthma & 595 & $12 \cdot 6$ \\
\hline CVD & 347 & $7 \cdot 3$ \\
\hline Arthritis & 1051 & $22 \cdot 2$ \\
\hline Osteoporosis & 215 & $4 \cdot 5$ \\
\hline Overweight $\left(\mathrm{BMI} \geq 25 \mathrm{~kg} / \mathrm{m}^{2}\right)$ & 2471 & $57 \cdot 3$ \\
\hline \multicolumn{3}{|l|}{ Physical activity } \\
\hline No activity & 788 & $17 \cdot 2$ \\
\hline Activity not sufficient ( $<150 \mathrm{~min} /$ week) & 1369 & $29 \cdot 9$ \\
\hline Sufficient activity ( $\geq 150 \mathrm{~min} /$ week) & 2420 & $52 \cdot 9$ \\
\hline \multicolumn{3}{|l|}{ Soft drink consumption (litre/d) } \\
\hline 0 & 3319 & $70 \cdot 0$ \\
\hline$<0.5$ & 828 & $17 \cdot 5$ \\
\hline$\geq 0.5$ & 594 & $12 \cdot 5$ \\
\hline \multicolumn{3}{|l|}{ Soft drink:total fluid ratio* } \\
\hline 0 & 3207 & $69 \cdot 5$ \\
\hline$<0 \cdot 2$ & 424 & $9 \cdot 2$ \\
\hline $0 \cdot 2-0 \cdot 3$ & 370 & $8 \cdot 0$ \\
\hline $0.3-0.5$ & 313 & $6 \cdot 8$ \\
\hline$\geq 0 \cdot 5$ & 304 & $6 \cdot 6$ \\
\hline \multicolumn{3}{|l|}{ Intake of fruit (servings/d) } \\
\hline$<2$ & 2641 & $55 \cdot 7$ \\
\hline$\geq 2$ & 2099 & $44 \cdot 3$ \\
\hline \multicolumn{3}{|l|}{ Intake of vegetables (servings/d) } \\
\hline$<5$ & 4217 & $89 \cdot 4$ \\
\hline$\geq 5$ & 501 & $10 \cdot 6$ \\
\hline
\end{tabular}

SA, South Australia; COPD, chronic obstructive pulmonary disease. *Total fluid includes soft drinks, water and fruit juice.

Using multivariate analysis (Table 3), after adjusting for sociodemographic factors, the intake of soft drinks was significantly associated with depression, stress, suicidal ideation and psychological distress. The odds ratios for stress, suicidal ideation and psychological distress comparing high consumption and non-consumption of soft drinks were all above 1.60. Additional adjustment for lifestyle, fruit and vegetable intakes, and chronic diseases slightly attenuated the association. All of the associations remained significant, except that between soft drinks and suicidal ideation which approached significance.

People with mental illnesses are more likely to report increased thirst ${ }^{(25,26)}$; therefore we examined the association between soft drink:total fluid ratio and mental 
Table 2 Prevalence of anxiety, depression, stress-related problem, suicidal ideation, psychological distress and current mental health condition according to soft drink intake among adults aged 16 years and above in South Australia, March 2008-December 2008

\begin{tabular}{|c|c|c|c|c|c|c|c|c|c|c|}
\hline & \multicolumn{4}{|c|}{ Soft drink consumption (litre/d) } & \multicolumn{6}{|c|}{ Soft drink:total fluid ratio* } \\
\hline & 0 & $<0.5$ & $\geq 0.5$ & $P$ & 0 & $<0 \cdot 2$ & $0.2-0.3$ & $0.3-0.5$ & $\geq 0.5$ & $P$ \\
\hline$n$ & 3319 & 828 & 594 & & 3207 & 424 & 370 & 313 & 304 & \\
\hline Anxiety (\%) & 4.9 & 5.5 & 6.5 & 0.431 & $5 \cdot 0$ & $4 \cdot 3$ & $6 \cdot 2$ & $9 \cdot 3$ & $4 \cdot 3$ & 0.071 \\
\hline Depression (\%) & $6 \cdot 1$ & $8 \cdot 1$ & $9 \cdot 6$ & 0.018 & $6 \cdot 1$ & $7 \cdot 8$ & $7 \cdot 1$ & $6 \cdot 8$ & $14 \cdot 1$ & 0.001 \\
\hline Stress-related problem (\%) & $3 \cdot 9$ & $5 \cdot 3$ & $6 \cdot 4$ & 0.056 & $3 \cdot 9$ & $4 \cdot 0$ & $6 \cdot 1$ & 4.9 & $8 \cdot 7$ & 0.030 \\
\hline Suicidal ideation (\%)† & $4 \cdot 0$ & $3 \cdot 9$ & $8 \cdot 4$ & 0.011 & $3 \cdot 9$ & $4 \cdot 4$ & $3 \cdot 2$ & $3 \cdot 5$ & $13 \cdot 0$ & 0.0001 \\
\hline Psychological distress (K10 score) (\%) & $7 \cdot 7$ & $10 \cdot 0$ & $15 \cdot 0$ & $<0.001$ & $7 \cdot 7$ & $9 \cdot 6$ & $8 \cdot 1$ & $17 \cdot 2$ & $15 \cdot 0$ & 0.0001 \\
\hline $\begin{array}{l}\text { Current mental health condition (diagnosed } \\
\text { and/or receiving treatment) (\%) }\end{array}$ & $12 \cdot 9$ & $15 \cdot 6$ & $18 \cdot 6$ & 0.008 & $13 \cdot 0$ & $14 \cdot 1$ & $16 \cdot 2$ & $15 \cdot 0$ & $23 \cdot 9$ & 0.001 \\
\hline
\end{tabular}

K10, Kessler Psychological Distress ten-item scale.

*Total fluid includes soft drinks, water and fruit juice.

tNine hundred and thirty-two participants did not respond.

Table 3 Odds ratios and $95 \%$ confidence intervals for anxiety, depression, stress-related problem, suicidal ideation, psychological distress and current mental health condition by soft drink consumption level among adults 16 years and above in South Australia, March 2008-December 2008

\begin{tabular}{|c|c|c|c|c|c|c|c|}
\hline & \multicolumn{6}{|c|}{ Soft drink intake (litre/d) } & \multirow[b]{3}{*}{$P$ for treno } \\
\hline & \multicolumn{2}{|c|}{0} & \multicolumn{2}{|c|}{$<0.5$} & \multicolumn{2}{|c|}{$\geq 0.5$} & \\
\hline & OR & $95 \% \mathrm{Cl}$ & OR & $95 \% \mathrm{Cl}$ & OR & $95 \% \mathrm{Cl}$ & \\
\hline \multicolumn{8}{|l|}{ Anxiety } \\
\hline Model $1^{*}$ & $1 \cdot 00$ & ref & $1 \cdot 17$ & $0.77,1 \cdot 80$ & $1 \cdot 43$ & $0.91,2 \cdot 25$ & $0 \cdot 116$ \\
\hline Model $2 \dagger$ & $1 \cdot 00$ & ref & $1 \cdot 13$ & $0 \cdot 70,1 \cdot 81$ & $1 \cdot 21$ & $0 \cdot 74,1 \cdot 98$ & 0.432 \\
\hline \multicolumn{8}{|l|}{ Depression } \\
\hline Model $1^{*}$ & $1 \cdot 00$ & ref & $1 \cdot 52$ & $1 \cdot 08,2 \cdot 15$ & 1.93 & $1 \cdot 29,2 \cdot 90$ & $<0.001$ \\
\hline Model $2 \dagger$ & 1.00 & ref & 1.52 & $1 \cdot 04,2 \cdot 21$ & $1 \cdot 63$ & $1 \cdot 03,2 \cdot 58$ & 0.016 \\
\hline \multicolumn{8}{|c|}{ Stress-related problem } \\
\hline Model $1^{*}$ & $1 \cdot 00$ & ref & 1.53 & $0.97,2.42$ & 1.98 & $1 \cdot 22,3 \cdot 24$ & 0.002 \\
\hline Model $2 \dagger$ & 1.00 & ref & 1.55 & $0.96,2 \cdot 50$ & $1 \cdot 79$ & $1 \cdot 06,3 \cdot 04$ & 0.014 \\
\hline \multicolumn{8}{|c|}{ Suicidal ideation } \\
\hline Model $1^{*}$ & $1 \cdot 00$ & ref & 0.96 & $0.55,1 \cdot 70$ & $2 \cdot 16$ & $1 \cdot 12,4 \cdot 17$ & 0.049 \\
\hline Model 2† & 1.00 & ref & $0 \cdot 88$ & $0.47,1 \cdot 65$ & $1 \cdot 87$ & $1 \cdot 03,3 \cdot 38$ & 0.067 \\
\hline \multicolumn{8}{|c|}{ Psychological distress (K10 score) } \\
\hline Model $1^{*}$ & $1 \cdot 00$ & ref & $1 \cdot 42$ & $1.04,1.94$ & $2 \cdot 34$ & $1 \cdot 59,3 \cdot 44$ & $<0.001$ \\
\hline Model $2 \dagger$ & $1 \cdot 00$ & ref & $1 \cdot 41$ & $0.99,2.00$ & $1 \cdot 72$ & $1 \cdot 11,2 \cdot 66$ & 0.008 \\
\hline \multicolumn{8}{|c|}{$\begin{array}{l}\text { Current mental health problem (diagnosed and/or } \\
\text { receiving treatment) }\end{array}$} \\
\hline Model $1^{*}$ & $1 \cdot 00$ & ref & $1 \cdot 44$ & $1 \cdot 11,1 \cdot 88$ & 1.95 & $1 \cdot 43,2 \cdot 65$ & $<0.001$ \\
\hline Model $2 \dagger$ & 1.00 & ref & $1 \cdot 42$ & $1 \cdot 07,1 \cdot 90$ & 1.59 & $1 \cdot 13,2 \cdot 23$ & 0.002 \\
\hline
\end{tabular}

K10, Kessler Psychological Distress ten-item scale; ref, reference category.

${ }^{*}$ Model 1 adjusted for age and gender.

tModel 2 adjusted for age, gender, education, income, area of residence, smoking (non-smoker, ex smoker, smoker), drinking (servings/d), physical activity (none, physical activity $<150$ or $\geq 150 \mathrm{~min} / \mathrm{d}$ ), overweight, diabetes, asthma, CVD, arthritis, osteoporosis, chronic obstructive pulmonary disease, intake of fruit and vegetables (servings/d).

illness. In the multivariate models (Table 4), comparing those with a soft drink:total fluid ratio $\geq 0.5$ with nonconsumers $($ ratio $=0)$, the odds ratios for depression, stress and suicidal ideation were all above $2 \cdot 00$. In the full model, there was a higher risk of psychological stress when the soft drink:total fluid ratio was $0 \cdot 3$. Excluding participants with chronic diseases in the multivariate analysis did not change the association (data not shown).

\section{Discussion}

In the current cross-sectional study we found that consumption of soft drinks was positively associated with mental health problems including depression, stress-related problem, suicidal ideation and psychological distress among adults living in South Australia. The association was significant in both men and women. Adjusting for socioeconomic status, lifestyle factors, and fruit and vegetable consumption did not change the association.

Soft drinks contain a large amount of sugar. In ecological studies, sugar is found to be related to a higher prevalence of depression ${ }^{(4)}$. Westover and Marangell hypothesised several possible mechanisms linking sugar and depression, including increased level of $\beta$-endorphins and oxidative stress ${ }^{(4)}$. It is well documented that increased visceral fat and insulin resistance are prevalent among depressed patients ${ }^{(10)}$, and are associated 
Table 4 Odds ratios and $95 \%$ confidence intervals for anxiety, depression, stress-related problem, suicidal ideation, psychological distress and mental health condition by ratio of soft drink to total fluid consumption among adults 16 years and above in South Australia, March 2008-December 2008

\begin{tabular}{|c|c|c|c|c|c|c|c|c|c|c|c|}
\hline & \multicolumn{10}{|c|}{ Soft drink:total fluid ratio } & \multirow[b]{3}{*}{$P$ for trend } \\
\hline & \multicolumn{2}{|c|}{$0(n 3207)$} & \multicolumn{2}{|c|}{$<0.2(n 424)$} & \multicolumn{2}{|c|}{$0.2-0.3(n 369)$} & \multicolumn{2}{|c|}{$0.3-0.5(n 313)$} & \multicolumn{2}{|c|}{$\geq 0.5(n 304)$} & \\
\hline & OR & $95 \% \mathrm{Cl}$ & OR & $95 \% \mathrm{Cl}$ & OR & $95 \% \mathrm{Cl}$ & OR & $95 \% \mathrm{Cl}$ & OR & $95 \% \mathrm{Cl}$ & \\
\hline \multicolumn{12}{|l|}{ Anxiety } \\
\hline Model $1^{*}$ & $1 \cdot 00$ & ref & $0 \cdot 86$ & $0.48,1.56$ & $1 \cdot 36$ & $0.79,2.35$ & $2 \cdot 10$ & $1 \cdot 19,3 \cdot 71$ & 0.96 & $0 \cdot 51,1 \cdot 80$ & 0.093 \\
\hline Model 2† & $1 \cdot 00$ & ref & $0 \cdot 82$ & $0.44,1.54$ & $1 \cdot 31$ & $0 \cdot 73,2 \cdot 35$ & $1 \cdot 87$ & $1 \cdot 00,3.53$ & $0 \cdot 77$ & $0 \cdot 37,1 \cdot 60$ & $0 \cdot 648$ \\
\hline \multicolumn{12}{|c|}{ 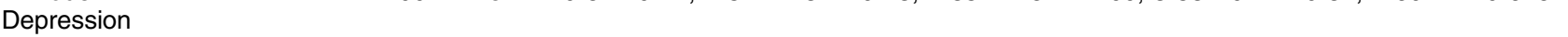 } \\
\hline Model $1^{*}$ & 1.00 & ref & $1 \cdot 45$ & $0.91,2.31$ & $1 \cdot 35$ & $0 \cdot 84,2 \cdot 18$ & $1 \cdot 30$ & $0 \cdot 71,2 \cdot 40$ & $2 \cdot 95$ & $1 \cdot 83,4 \cdot 76$ & $<0.001$ \\
\hline Model 2† & $1 \cdot 00$ & ref & $1 \cdot 48$ & $0.91,2.42$ & $1 \cdot 33$ & $0 \cdot 81,2 \cdot 21$ & $1 \cdot 22$ & $0 \cdot 62,2 \cdot 38$ & $2 \cdot 25$ & $1 \cdot 32,3 \cdot 84$ & 0.004 \\
\hline \multicolumn{12}{|c|}{ Stress-related problem } \\
\hline Model $1^{*}$ & $1 \cdot 00$ & ref & $1 \cdot 12$ & $0 \cdot 61,2 \cdot 04$ & $1 \cdot 79$ & $0 \cdot 95,3 \cdot 36$ & $1 \cdot 44$ & $0 \cdot 70,2 \cdot 95$ & $2 \cdot 71$ & $1 \cdot 51,4 \cdot 86$ & 0.001 \\
\hline Model 2† & 1.00 & ref & $1 \cdot 18$ & $0 \cdot 64,2 \cdot 16$ & $1 \cdot 78$ & $0.92,3.44$ & $1 \cdot 56$ & $0.73,3.33$ & $2 \cdot 21$ & $1 \cdot 14,4 \cdot 28$ & 0.006 \\
\hline \multicolumn{12}{|c|}{ Suicidal ideation } \\
\hline Model $1^{*}$ & $1 \cdot 00$ & ref & $1 \cdot 09$ & $0 \cdot 54,2 \cdot 21$ & $0 \cdot 78$ & $0 \cdot 34,1 \cdot 78$ & $0 \cdot 83$ & $0 \cdot 35,2 \cdot 00$ & $3 \cdot 49$ & $1 \cdot 68,7 \cdot 23$ & 0.023 \\
\hline Model 2† & $1 \cdot 00$ & ref & $1 \cdot 04$ & $0 \cdot 49,2 \cdot 18$ & $0 \cdot 89$ & $0 \cdot 38,2 \cdot 11$ & 0.53 & $0 \cdot 21,1 \cdot 36$ & $2 \cdot 85$ & $1 \cdot 44,5 \cdot 64$ & 0.034 \\
\hline \multicolumn{12}{|c|}{$\begin{array}{l}\text { Psychological distress } \\
\text { (K10 score) }\end{array}$} \\
\hline Model $1^{*}$ & $1 \cdot 00$ & ref & $1 \cdot 35$ & $0 \cdot 89,2 \cdot 04$ & $1 \cdot 16$ & $0 \cdot 73,1 \cdot 85$ & $2 \cdot 78$ & $1 \cdot 72,4 \cdot 49$ & $2 \cdot 38$ & $1 \cdot 40,4 \cdot 05$ & $<0.001$ \\
\hline Model $2 \dagger$ & $1 \cdot 00$ & ref & $1 \cdot 49$ & $0 \cdot 96,2 \cdot 31$ & $1 \cdot 15$ & $0 \cdot 70,1 \cdot 90$ & $2 \cdot 42$ & $1 \cdot 36,4 \cdot 31$ & $1 \cdot 25$ & $0 \cdot 73,2 \cdot 13$ & 0.042 \\
\hline \multicolumn{12}{|c|}{$\begin{array}{l}\text { Current mental health problem } \\
\text { (diagnosed and/or receiving } \\
\text { treatment) }\end{array}$} \\
\hline Model $1^{*}$ & $1 \cdot 00$ & ref & $1 \cdot 26$ & $0 \cdot 89,1 \cdot 80$ & $1 \cdot 53$ & $1 \cdot 06,2 \cdot 22$ & $1 \cdot 45$ & $0 \cdot 95,2 \cdot 21$ & $2 \cdot 65$ & $1 \cdot 81,3 \cdot 89$ & $<0.001$ \\
\hline Model 2† & $1 \cdot 00$ & ref & $1 \cdot 27$ & $0 \cdot 88,1 \cdot 84$ & $1 \cdot 50$ & $1 \cdot 00,2 \cdot 25$ & $1 \cdot 29$ & $0 \cdot 81,2 \cdot 07$ & $2 \cdot 05$ & $1 \cdot 34,3 \cdot 13$ & $<0.001$ \\
\hline
\end{tabular}

K10, Kessler Psychological Distress ten-item scale; ref, reference category.

${ }^{*}$ Model 1 adjusted for age and gender.

tModel 2 adjusted for age, gender, education, income, area of residence, smoking (non-smoker, ex smoker, smoker), drinking (servings/d), physical activity (none, physical activity $<150$ or $\geq 150 \mathrm{~min} / \mathrm{d}$ ), overweight, diabetes, asthma, CVD, arthritis, osteoporosis, chronic obstructive pulmonary disease, intake of fruit and vegetables (servings/d).

with oxidative stress, and increased inflammation and circulating cytokines are associated with depression. Because the glycaemic index of soft drinks is high, a large intake increases the total glycaemic load. In animal studies, intake of sucrose-sweetened water induces insulin resistance and exacerbates memory deficits ${ }^{(27)}$. In a population study, sugar-sweetened drink consumption was positively associated with fasting insulin ${ }^{(9)}$. It is also possible that soft drink consumption increases the risk of obesity, diabetes and other chronic diseases ${ }^{(6,7)}$, which in turn increases the risk of mental illness. Other chemicals in soft drinks may also play a role, but further research is needed to elucidate this.

Despite this evidence, human data regarding the association between soft drink consumption and mental illness are sparse. To our knowledge the current study is the first cross-sectional study suggesting a positive association between soft drink consumption and mental illness among adults. The results are consistent with findings among adolescents ${ }^{(14)}$. In the current study, with the exception of anxiety, the outcome measures in the logistic regression including depression, stress, suicidal ideation and psychological distress, based on the K10, were all highly significantly associated with soft drink consumption. Comparing high intake $v$. non-intake of soft drinks, the odds for depression, stress, suicidal ideation and psychological stress were all around 1.6. It is known that consumption of soft drinks increases the risk of chronic diseases including overweight and diabetes which are related to inflammation. At the same time, chronic diseases like diabetes ${ }^{(28)}$ and asthma ${ }^{(29)}$ are related to mental illness. Thus the association between soft drinks and mental health/illness could be confounded by these chronic conditions. In the present study, however, the association between soft drink consumption and mental illness did not change after we adjusted for having at least one of five chronic diseases. Furthermore, excluding those with chronic diseases did not change the association.

Risk behaviours often cluster and therefore soft drink consumption may be a marker of other dietary and lifestyle factors. The associations remained significant except for suicidal ideation which still approached significance, albeit attenuated, after adjusting for some lifestyle and sociodemographic factors.

There are a number of potential shortcomings in the study and caution should be exercised in interpreting its findings. The response rate of $62 \cdot 1 \%$ may limit generalisability, although the weighting of the data counteracts the non-response bias. In addition, other studies undertaken using SAMSS data have indicated comparable estimates across a range of measures ${ }^{(30-34)}$, and the prevalence of overweight was similar to that in the AusDiab study in Australian adults aged 25 years and above $(57 \cdot 3 \% \text { v. } 59 \cdot 8 \%)^{(35)}$. The cross-sectional study design precludes the establishment of causal relationships and 
the direction of those relationships. It is also pertinent that much of the information obtained relies on self-report. Indeed, under-reporting of body weight is common among obese participants ${ }^{(36)}$ and adjusting for BMI may not be free of residual confounding. Information on hot drinks (tea and coffee) was not collected, and although the majority of soft drinks sold in Australia are sugarsweetened, we did not have data to determine whether the increased intake was limited to sugared soft drinks, diet soft drinks or included both. We also did not have detailed information on the intake of other dietary factors known to be related to mental health, e.g. $n-3$ fatty acids ${ }^{(2,5)}$. It is acknowledged that these are potentially important issues, and although adjusting for fruit and vegetable consumption may to some degree have controlled for the diet quality, further studies incorporating these other variables should be pursued.

Notwithstanding these caveats, strengths of the study include its large and representative sample, the use of different outcome measures related to mental health problems, and the consistency of the relationships.

\section{Conclusions}

The current study provided novel evidence that increased soft drink consumption is associated with mental health problems among adults in Australia. Whether this relates directly to the sugar content, or some other pleasurable quality of soft drinks, remains to be determined; as does the temporal relationship to the onset of depression, as well as its severity and natural history. Regardless of the cause-andeffect relationship, the public health implications of consumption of large volumes of soft drinks are substantial from both a mental health and a metabolic perspective.

\section{Acknowledgements}

Sources of funding: The study was funded by the South Australian Department of Health. The study sponsors did not contribute to the study design and had no role in data collection, data analysis, data interpretation, or writing of the report. Conflict of interest declaration: Nil. Author contributions: A.W.T., T.K.G. and Z.S. participated in the concept and design of the study. Z.S., A.W.T., G.W., R.G. and T.K.G. participated in the interpretation of data and revision of the paper. Z.S. analysed the data and wrote the report. The corresponding author had full access to all data in the study and had final responsibility for the decision to submit for publication.

\section{References}

1. Bamber DJ, Stokes CS \& Stephen AM (2007) The role of diet in the prevention and management of adolescent depression. Nutr Bull 32, 90-99.
2. Bodnar LM \& Wisner KL (2005) Nutrition and depression: implications for improving mental health among childbearing-aged women. Biol Psychiatry 58, 679-685.

3. Sanchez-Villegas A, Henriquez $\mathrm{P}$, Bes-Rastrollo $\mathrm{M}$ et al. (2006) Mediterranean diet and depression. Public Health Nutr 9, 1104-1109.

4. Westover AN \& Marangell LB (2002) A cross-national relationship between sugar consumption and major depression? Depress Anxiety 16, 118-120.

5. Colangelo LA, He K, Whooley MA et al. (2009) Higher dietary intake of long-chain omega-3 polyunsaturated fatty acids is inversely associated with depressive symptoms in women. Nutrition 25, 1011-1019.

6. Vartanian LR, Schwartz MB \& Brownell KD (2007) Effects of soft drink consumption on nutrition and health: a systematic review and meta-analysis. Am J Public Health 97, 667-675.

7. Malik VS, Schulze MB \& Hu FB (2006) Intake of sugarsweetened beverages and weight gain: a systematic review. Am J Clin Nutr 84, 274-288.

8. Gill TP, Rangan AM \& Webb KL (2006) The weight of evidence suggests that soft drinks are a major issue in childhood and adolescent obesity. Med J Aust 184, 263-264.

9. Yoshida M, McKeown NM, Rogers G et al. (2007) Surrogate markers of insulin resistance are associated with consumption of sugar-sweetened drinks and fruit juice in middle and older-aged adults. $J$ Nutr 137, 2121-2127.

10. Timonen M, Laakso M, Jokelainen J et al. (2005) Insulin resistance and depression: cross sectional study. BMJ 330, $17-18$.

11. Anderson RJ, Freedland KE, Clouse RE et al. (2001) The prevalence of comorbid depression in adults with diabetes: a meta-analysis. Diabetes Care 24, 1069-1078.

12. Kozhimannil KB, Pereira MA \& Harlow BL (2009) Association between diabetes and perinatal depression among low-income mothers. JAMA 301, 842-847.

13. Atlantis E \& Baker M (2008) Obesity effects on depression: systematic review of epidemiological studies. Int $J$ Obes (Lond) 32, 881-891.

14. Lien L, Lien N, Heyerdahl S et al. (2006) Consumption of soft drinks and hyperactivity, mental distress, and conduct problems among adolescents in Oslo, Norway. Am J Public Health 96, 1815-1820.

15. Kendrick T, Dunn N, Robinson S et al. (2008) A longitudinal study of blood folate levels and depressive symptoms among young women in the Southampton Women's Survey. J Epidemiol Community Health 62, 966-972.

16. Atlantis E, Goldney RD \& Wittert GA (2009) Obesity and depression or anxiety. BMJ 339, b3868.

17. South Australian Department of Health (2002) South Australian Monitoring and Surveillance System (SAMSS). Population Research and Outcome Studies, Brief Report no. 2002-20. http://www.health.sa.gov.au/pros/portals/0/ BR\%202002-20\%20SAMSS.pdf (accessed December 2009).

18. Australian Bureau of Statistics (2004) Estimated Residential Population By Age and Sex. Canberra: AGPS.

19. Goldberg DP \& Hillier VF (1979) A scaled version of the General Health Questionnaire. Psychol Med 9, 139-145.

20. Goldney RD, Wilson D, Dal Grande E et al. (2000) Suicidal ideation in a random community sample: attributable risk due to depression and psychosocial and traumatic events. Aust N Z J Psychiatry 34, 98-106.

21. Watson D, Goldney R, Fisher L et al. (2001) The measurement of suicidal ideation. Crisis 22, 12-14.

22. Kessler R \& Mroczek D (1994) Final Versions of our Non-specific Psychological Distress Scale. Ann Arbor, MI: Institute for Social Research, University of Michigan.

23. National Health and Medical Research Council (2003) Dietary Guidelines for Australian Adults. Canberra: NHMRC. 
24. Gill T \& Taylor A (2004) Physical Activity Council Research Panel. Physical Activity in South Australian Adults. Adelaide: South Australian Department of Health.

25. Siegel AJ (2008) Hyponatremia in psychiatric patients: update on evaluation and management. Harv Rev Psychiatry 16, 13-24.

26. Siegel AJ, Baldessarini RJ, Klepser MB et al. (1998) Primary and drug-induced disorders of water homeostasis in psychiatric patients: principles of diagnosis and management. Harv Rev Psychiatry 6, 190-200.

27. CaO D, Lu H, Lewis TL et al. (2007) Intake of sucrosesweetened water induces insulin resistance and exacerbates memory deficits and amyloidosis in a transgenic mouse model of Alzheimer disease. J Biol Chem 282, 36275-36282.

28. Goldney RD, Phillips PJ, Fisher LJ et al. (2004) Diabetes, depression, and quality of life: a population study. Diabetes Care 27, 1066-1070.

29. Goldney RD, Ruffin R, Fisher LJ et al. (2003) Asthma symptoms associated with depression and lower quality of life: a population survey. Med J Aust 178, 437-441.

30. Dal Grande E, Gill T, Wyatt L et al. (2009) Population attributable risk (PAR) of overweight and obesity on chronic diseases: South Australian representative, crosssectional data, 2004-2006. Obes Res Clin Pract 3, 159-168.
31. Collins JE, Gill TK, Chittleborough CR et al. (2008) Mental, emotional, and social problems among school children with asthma. J Asthma 45, 489-493.

32. Hugo G, Taylor AW \& Dal Grande E (2008) Are baby boomers booming too much? An epidemiological description of overweight and obese baby boomers. Obes Res Clin Pract 2, 203-214.

33. Chittleborough CR, Taylor AW, Baum FE et al. (2009) Monitoring inequities in self-rated health over the life course in population surveillance systems. Am J Public Health 99, 680-689.

34. Goldney RD, Dunn KI, Air TM et al. (2009) Relationships between body mass index, mental health, and suicidal ideation: population perspective using two methods. Aust N Z J Psychiatry 43, 652-658.

35. Cameron AJ, Welborn TA, Zimmet PZ et al. (2003) Overweight and obesity in Australia: the 1999-2000 Australian Diabetes, Obesity and Lifestyle Study (AusDiab). Med J Aust 178, 427-432.

36. Taylor AW, Grande ED, Gill TK et al. (2006) How valid are self-reported height and weight? A comparison between CATI self-report and clinic measurements using a large cohort study. Aust N Z J Public Health 30, $238-246$. 